MATEC Web of Conferences 44, 02009 (2016)

DOI: $10.1051 /$ matecconf/20164402009

(C) Owned by the authors, published by EDP Sciences, 2016

\title{
Research on pipe welding information management system based on RFID
}

\author{
Xun Liu ${ }^{1, a}$ \\ ${ }^{1}$ Chengdu Qianjia technology Co.,Ltd, Institute of Technology, China
}

\begin{abstract}
This paper introduces the construction background, construction target and construction principle of the pipe welding management system based on RFID. Then, describes the specific requirements of the system. The basic principle and key technology of the system are introduced. The structure of the system (including the system design, the selections of handheld devices and high frequency passive RFID tags) is described . Then the system management software designs (including software structure, the main functions of the management center system and the main functions of the handheld detection system) are described in detail. Finally, the management system is implemented, and it is deployed to several Gas Co, which has chieved good results.
\end{abstract}

\section{Introduction}

With the construction of gas pipeline network, different welding parameters are different. For pipe welding, supervision, maintenance and management personnel, how to quickly know the pipe welding parameters, pipe fittings, welding inspection results and other information, is an important issue to be solved in the current management of gas pipeline network. With the continuous development of the refinement, centralization, standardization and informatization of the management of Gas Co., the information management of the pipe welding based on RFID ${ }^{[1]}$ radio frequency tag technology has become the development trend of the tube information management of the Gas Co.

The specific objectives of the management system are as follows:

a.the establishment of a set of pipe welding information management system to ensure that the welding information is comprehensive, standardized, accurate, and real-time.

b.the implementation of the initialization, the sending sign and changing sign of the RFID tag, writing into and reading out the welding parameters.

c.the implementation of writing into and reading out the pipe welding inspection information

d.the implementation of the dynamic monitoring and management of the whole network pipe fitting and welding information.

e.the implementation of the electron of the tube inspection and maintenance, in order to facilitate the maintenance data management

f. the implementation of a complete and powerful report, statistical analysis and query functions, to provide the decision-making basis for the relevant departments.
The construction principles of the management system are as follows:

a. stability

Because it is a very important system of pipe network construction and daily maintenance, it must be able to run continuously.The system is based on economic and practical, cost-effective design principles. Comprehensive considering system structure, design scheme and technical support, the $\mathrm{B} / \mathrm{S}^{[2]}$ structure is adopted.The establishment of a separate database and application server, ensure the stability and reliability of the system.

Hardware must be fully considered according to the environment, and use the industrial grade RFID read and write equipment to ensure the stability of the system.

b. progressiveness

The system uses full WEB pages and advanced WEB GIS ${ }^{[3]}$ technology.

RFID read and write devices integrated with RFID, GPRS and WiFi functions, better meet the actual needs of the maintenance management personnel, and lay a good foundation for the system to increase the field repair and maintenance functions.

c. maintenance convenience

Use free Baidu MAP or GIS to provide information for the pipeline maintenance management, and provide the handheld equipment for the supervision, pipe fittings maintenance and management personnel to read the pipe welding parameters.

d openness, compatibility

All kinds of design specifications, technical indicators and products are in line with international and industrial standards. All the products used in the system must are open and compatible systems, can be compatible with the products of different manufacturers, and could effectively protect the investment of the Gas Co..

\footnotetext{
a Xun liu:1538768111@qq.com
} 
e. operation convenience

The system is simple, with friendly interface, easy to install and debug, meet the requirements of different people.

\section{REQUIREMENT ANALYSIS}

After the completion of the pipe welding and detection, pipeline maintenance management personnel will write welding parameters, welding, testing and other information into RFID tags through the handheld device, and then insert the RFID tag into the RFID tab and do a fixed processing. Specific requirements are as follows: a. can input the information complied with ISO 12176-4: $2003^{[4]}$ standard requirements, including production date, batch of raw materials, production processes and all other production-related information into the chip, and achieve permanent traceability function.

b. the library information, including order number, number of shipments, shipping customer name, shipping date and other information can be entered into RFID tag, also saved to pipe welding information management system.

c. the information including the actual pipe welding parameters, welding date, time, ambient temperature, welders work number and other information is read by a hand held device connected to the welder, and is uploaded to the pipe welding information management system. Welding parameter file is created to facilitate the supervision personnel to inspect the welding parameters, at the same time, it can be used as a reason to find the problem and as the basis for determining the responsibility if there is a leak in the future.

d. product tracking and recognition, that is, after the completion of the project, in line operation, through the handheld reader, management and maintenance personnel can detect the specific location of the target tube, and quickly identify the specific information of the product. In the case of no more than $20 \mathrm{~cm}$ of soil covering, effective detection distance is within $3 \mathrm{~m}$.

\section{SYSTEM SURVEY}

\subsection{Basic principles of the system}

According to the project requirements, the system is designed for the installation of RFID electronic tags for welding, pipe fittings and other information preservation, as well as tracking and identifying the fittings. Engineering supervision and pipeline maintenance and management personnel read welding, pipe fittings and other information saved on the RFID tags, and by combining with wireless network (WIFI or GPRS network) and pipe welding information management system complete the welding-related information query and fittings position tracing and identification.

a. fittings archives information management

After the pipe out of the library and the completion of the welding, pipe engineering management personnel need to establish a pipe information file for each welding pipe. At the same time, the information of pipe fitting and welding parameters in demand is saved to a central management system, and alse is written to the RFID tag. b. pipe welding information check

Engineering supervision and pipeline maintenance and management personnel can read the information in the RFID tag buried in the pipe through handheld devices, and combining with central management system, check the pipe fitting and welding information file.

c. pipe tracing and identification

In the process of the pipeline maintenance management, when the tube is in the case of no more than $20 \mathrm{~cm}$ cement and soil buried, pipeline maintenance managers can read the information in RFID tag embedded in the fittings through a handheld device, and combing with the GIS map find the fitting, and identify the relevant information.

$\mathrm{d}$ pipe line visualization management

Through the establishment of GIS system of the pipe line and terrain of the corresponding area, and electronic account of fittings, combining with geographical position and surrounding environment of the pipeline and energy facilities in the GIS platform, pipeline managers can view basic properties, maintenance records, working status, welding parameters, and so on, to achieve visualization of pipe line management. At the same time, the electronic accounting information and location information are downloaded to the handheld device for the maintenance and management personnel to check at the scene, and provide strong information support for field maintenance and maintenance.

\subsection{System key technology}

\subsubsection{RFID radio frequency data storage and communication}

Each RFID tags can provide a unique serial number encoding, and can be stored for a long time to write the data information, and with a variety of packaging methods, suitable for use in the field environment. The RFID electronic tag is powered by a handheld device in a wireless way, and the data communication between handheld device and the electronic tag is realized in the RF mode.

\subsubsection{GPRS network communication}

GPRS (General Packet Radio Service ) is compared with the traditional GSM transmission mode, with "high speed transmission", "on-line forever", "charge according to quantity" and "freely switch" advantages, to enhance the quality of mobile communication.

\subsubsection{GIS geographic information system}

GIS is a new technology which has developed rapidly in recent years. GIS is a product of the interdisciplinary use of cartography, computer science, 
geography, remote sensing, statistics, surveying and mapping, communication, planning and management, and widely used in various fields. In this system, it is mainly used in the computer system to display and manage the map and the pipe line information.

\section{System Components}

\subsection{System composition}

Pipe welding information management system is made up of three parts, that is, the handheld device, electronic information tag and system management center.

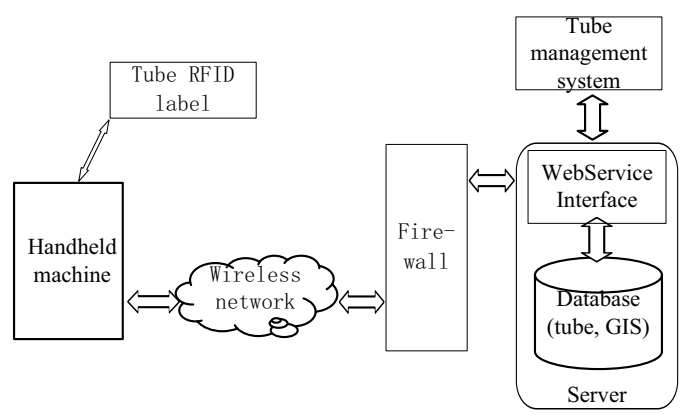

Figure.1 Overall system design

According to the requirements of the project and the use environment, the hand-held device uses a IP64 industrial grade hand-held inspection instrument, while the electronic tags of passive type and full seal design are used, the software uses $\mathrm{B} / \mathrm{S}$ structure (web browsing mode) design.

A RFID tag is installed on each of the welded joints of the pipe fitting, each pipe welding management personnel holds an industrial PDA, and each project supervisor or pipeline maintenance administrator holds an industrial PDA.

\subsection{Hardware introduction}

\subsection{1 hand-held inspection instrument GRT-PDA}

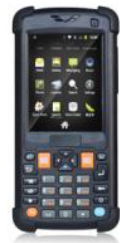

Figure.2 GRT-PDA

The main features are as follows:

a. industrial grade three proof design, fall proof,water proof and dust proof.

b. integrate RFID, GPRS, GPS and other modules.

c. built-in camera.

d. built in CE WIN operating system and powerful inspection software.

e. with a touch screen and the full function 32 key keyboard, can input information and operate software by hand written or keyboard. f. large storage memory, place the massive information database of the electronic account, photos, maintenance records of all pipeline and energy facilities.

g. through the inspection software based on WIN CE platform, can easily query electronic account, inspection plan, find the facility near the current location, and can fill in and declare a complex inspection work content, and upload the photos.

\subsubsection{High frequency passive RFID Tags}
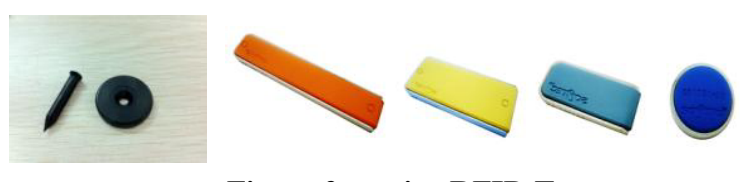

Figure.3 passive RFID Tags

Label shape: can be customized according to the design of pipe fittings, form is be shown in the Figure 3 above.

Storage capacity: 8Kbit, 16 partitions, each partition has two passwords.

Working frequency: 13.56MHZ

Communication speed: 106Kboud

Read and write distance: 5-10CM

Erasing times: $>100000$ times

Data preservation: $>10$ years

Packaging Materials: PVC、PET

Packaging technology: ultrasonic automatic wire and auto touch welding.

Production standard: ISO14443[5][6].

\subsubsection{Installation scheme of passive RFID tag}

In order to ensure that the RFID tag is installed at the fitting interface, and the communication distance is not affected by the handheld device to read the RFID tags, in manufacturing the tube, a RFID tag slot (can be rectangular, square, circles, etc.) with $2.5 \mathrm{~mm}$ concave section in the interface is reserved. In this way, after the completion of the pipe welding, pipe welding engineering management personnel will write welded information written into RFID tags, and insert the tag into the slot, and then seal the slot with the sealing glue.

\section{Design and implementation of system management software}

\subsection{Software structure}

The software use the advanced $\mathrm{B} / \mathrm{S}$ structure, the SQLSERVER, WEBGIS and other core development technology, and the terrain road map uses Baidu MAP.

(Baidu GIS is free road terrain MAP information, will do some updates every year, when the user has not set up or purchase mapping road terrain data, it is the ideal choice, can provide more accurate road terrain information, and can save a lot cost of buying maps and annual renewal for users, also avoid the possible occurrence of map information copyright law disputes.) 


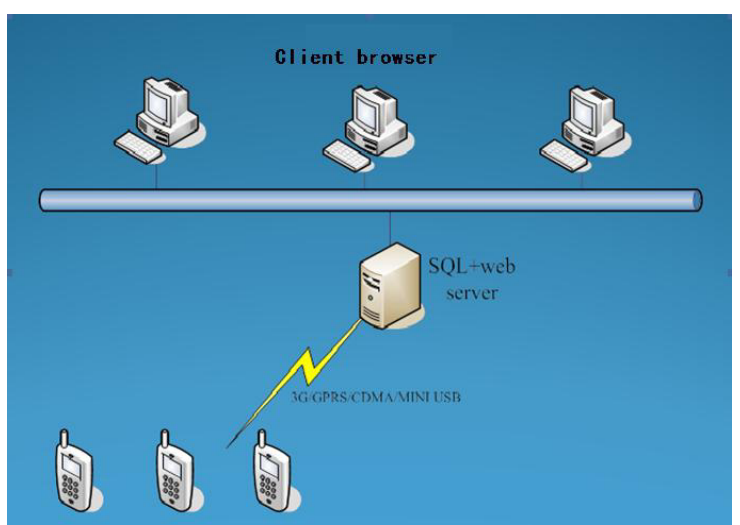

Figure.4 Software network structure sketch map

Fittings information, welding information, the welding parameters, weld inspection data and other management information are unified sent to and stored in a single database server, and through the server the software is published in Web page. Users can directly use the software with the browser in any computer by local area networks or network, do not need to install any client software. This not only greatly improve the convenience of the user of the software, but also strengthen the stability of the system, ensure the safety and reliability of the system data, and avoid the instability of the system caused by the client software, while the maintenance workload greatly is reduced.

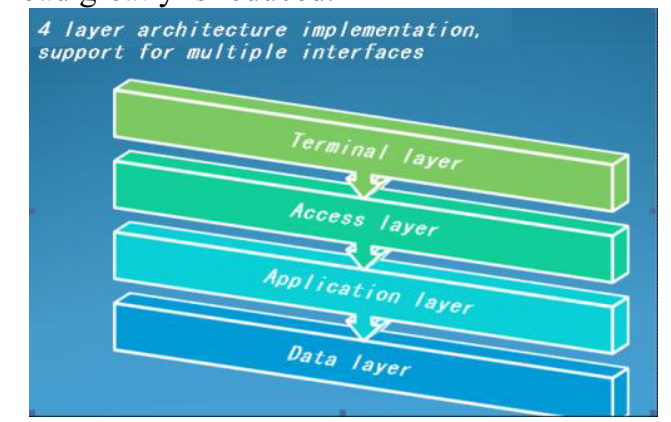

Figure.5 Software structure sketch map 1

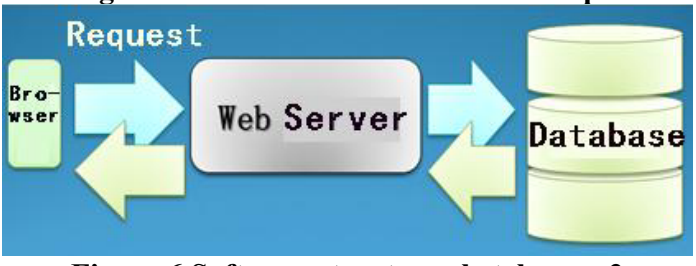

Figure.6 Software structure sketch map 2

\subsection{Software main function}

\subsubsection{Management center system function}

The main functions of the center system are as follows: Fittings archives information management: support for tube production, procurement, storage, welding, welding parameters, testing, use and maintenance of information management.

Pipe welding and tracing GIS management: support for the map display of the deployment of the pipe and the welding distribution, also through GIS providing the fittings geographic information for pipeline maintenance and management personnel.
Sending sign: bind the RFID tag with the tube, and write the fitting information to the RFID tag.

Handheld device data download: via WIFI or GPRS the pipe welding information, sending note information, fittings geographic information and other relevant information are download to the handheld devices.

Statistical Analysis : support for a multi dimensional analysis on the installation, use, maintenance and welding related information of the fittings of the Gas Co.

\subsection{2 hand-held inspection system function}

The main functions of the handheld system are as follows: Data upload and download: via WIFI or GPRS upload and download the pipe welding information, send note information, fittings geographic information and other relevant information from center management system.

Send sign: bind the RFID tag with the tube, and write the fitting information to the RFID tag.

Welding information inspection: by reading the RFID tag to obtain the information of the welding information, welding parameters and so on.

Pipe tracing: by downloading the GIS information of the location fitting, and using the RFID tag reading detection function to find the pipe within 3 meters.

Welding parameters upload and download: through data exchange with the welder, the welding parameters of the welder are downloaded, and the welding parameters of the specified tube is also uploaded to the welder in order to set the welding parameters of welder.

\section{Conclusion}

The construction background, needs, principles and key techniques of the pipe welding information management system based on RFID are analyzed, The overall structure design of the system is carried out. The corresponding hardware devices are selected. The design and the implementation of the system are carried out. At present, the system has been used in some Gas Co, and has achieved good economic and social benefits.

\section{References}

1. Y.F. Dan, C.G. Dan, L. Yao, Radio Frequency Identification (RFID) Principles and Applications,( Electronics Industry Press,2013).

2. J.N.Wang,Software $B / S$ development,(Tsinghua University press,2012).

3. P. A. Longley, M. F. Goodchild, D. J. Maguire, D. W. Rhind,Geographic Information Science and Systems 4th Edition,(VILEY,2011).

4. ISO12176-4:2003:Plastics pipes and fittings-Equipment for fusion jointing polyethylene systems - Part 4: Traceability coding.

5. ISO/IEC 14443-1:2008 Identification cards-Contactless integrated circuit cards--Proximity cards-Part 1: Physical characteristics.

6. ISO/IEC 14443-2:2010 Identification cards-Contactless integrated circuit cards--Proximity cards-Part 2:Radio frequency power and signal interface. 